\title{
Early Non-Destructive Biofouling Detection in Spiral Wound RO Membranes using a Mobile Earth's field NMR
}

\author{
E.O. Fridjonsson ${ }^{1}$, S.J. Vogt ${ }^{1}$, J.S. Vrouwenvelder ${ }^{2-4}$, and M.L. Johns ${ }^{1 *}$ \\ ${ }^{1}$ School of Mechanical and Chemical Engineering, The University of Western Australia, \\ Crawley, WA 6009, Australia. \\ ${ }^{2}$ Wetsus, Centre of Excellence for Sustainable Water Technology, Agora 1, P.O. Box 1113, \\ 8900 CC Leeuwarden, The Netherlands. \\ ${ }^{3}$ Department of Biotechnology, Faculty of Applied Sciences, Delft University of Technology, \\ Julianalaan 67, 2628 BC Delft, The Netherlands. \\ ${ }^{4}$ Biological and Environmental Sciences and Engineering Division, Water Desalination and \\ Reuse Center, King Abdullah University of Science and Technology, Thuwal 23955-6900, \\ Saudi Arabia.
}

\begin{abstract}
We demonstrate the use of Earth's field (EF) Nuclear Magnetic Resonance (NMR) to provide early non-destructive detection of active biofouling of a commercial spiral wound reverse osmosis (RO) membrane module. The RO membrane module was actively biofouled to different extents, by the addition of biodegradable nutrients to the feed stream, as revealed by a subtle feed-channel pressure drop increase. Easily accessible EF NMR parameters (signal relaxation parameters $T_{1}, T_{2}$ and the total NMR signal modified to be sensitive to stagnant fluid only) were measured and analysed in terms of their ability to detect the onset of biofouling. The EF NMR showed that fouling near the membrane module entrance significantly distorted the flow field through the whole membrane module. The total NMR signal is shown to be suitable for non-destructive early biofouling detection of spiral wound membrane modules, it was readily deployed at high (operational) flow rates, was particularly sensitive to flow field changes due to biofouling and could be deployed at any position along the membrane module axis. In addition to providing early fouling detection, the mobile EF NMR apparatus could also be used to (i) evaluate the production process of spiral wound membrane modules, and (ii) provide an in-situ determination of module cleaning process efficiency.
\end{abstract}

*Corresponding Author: Ph: +61 864885664 ; E-mail: michael.johns@uwa.edu.au 
Keywords: Reverse osmosis; biofouling; early detection; Earth's field NMR; fouling control strategies. 


\section{Introduction}

Highly populated areas and arid zones around the world suffer from vulnerability to freshwater availability. It has been projected (in 2013) by the Food and Agricultural Organization of the United Nations [1] that by 2025 there will be 1.8 billion people living in countries or regions with absolute water scarcity, and two-thirds of the world population could be under water stress conditions. Traditional water sources in the future will need to be supplemented in order to meet the projected increase in water consumption. Reverse osmosis (RO) membrane technology has developed over the past 40 years to account for $80 \%$ of the total desalination plants installed worldwide [2] with strong growth expected into the future to meet further demand [3]. Although many advances have been made, membrane fouling continues to be a major concern for the desalination industry (e.g. [4-8]) as it decreases membrane performance, requires frequent chemical cleaning and shortens the membrane lifespan. It poses a major economic burden on plant operation, estimated at $25-50 \%$ of total plant operating costs $[9,10]$.

Of the four main types of fouling [11]: Inorganic, organic, particulate and microbiological, only microbiological (or biofouling) can arguably be significantly reduced by pre-treatment alone $[12,13]$. Biofouling occurs extensively, even with significant pretreatment [14]. This is attributed to the formation of biofilms on membrane and feed spacer sheet surfaces within the spiral wound membrane modules, which once established are capable of re-emergence even after intensive chemical treatment [15]. Biofilms are an accumulation of micro-organisms and extracellular material which forms a matrix which is irreversibly bonded onto the membrane and/or feed spacer surface, with the main mechanism for cohesion and adhesion of the biofilm matrix due to the extracellular polymeric substances (EPS), which makes up 50-80\% of the organic matter $[15,16]$. Biofilms go through three stages of growth: the induction phase, growth phase and plateau phase; it is crucial to detect and stop biofilm growth during the adhesion-dominated induction phase to effectively prevent biofouling [17]. During the growth phase the biofilm increases predominantly by bacterial cell multiplication with this phase being typically associated with biofouling (or the threshold of interference) where up to $25 \%$ reduction in permeate flux has been observed due to hydraulic resistance from the EPS matrix and concentration polarisation across the membrane surface [16]. The type of flow regime within the RO membrane affects the stability, adhesive strength, density and 
structure of the biofilm [18], with 'fluffy' biofilm growth occurring at low Reynolds numbers $(R e)$ while high $R e$ induces the formation of thin, compact, harder to remove biofilms [10]. The biofilm growth inhibits convective transport [19], increasing flow resistance which causes a back-bone (or telescoping) flow regime to emerge [20-22].

As membrane biofouling causes reduced separation efficiency, permeate contamination, membrane deterioration and increased energy costs it is a common reason for early disposal of RO membrane modules [17]. Vrouwenvelder et al. [10, 23] estimate that a warning detection system sufficiently sensitive to detect early stages of biofouling (i.e. before the biofilm becomes established within the membrane) could reduce energy costs by up to 5\%, and decrease the annual membrane replacement and cleaning costs by up to $10 \%$. Vrouwenvelder et al. $[24,25]$ showed that biofilm accumulation in RO membrane elements increased the feed side pressure drop between the inlet and the salty discharge outlet of the module (hereafter referred to as the feed-channel pressure drop). According to Flemming et al. [20] commonly used measurement techniques such as monitoring permeate flux decrease, colony count and membrane autopsy are not sensitive to detect early stages of biofouling or do not provide insitu non-invasive quantitative information about the level of fouling through membrane module or pressure vessel containing membrane modules. Direct observation technique [26] and impedance spectroscopy [27] have recently been used to characterise fouling. A membrane fouling simulator (MFS) can also be operated in parallel to the actual RO membrane system [11]; previous research [10] has found that MFS closely follow the biofouling effects inside the RO membrane modules.

Here we consider the use of a low cost, portable non-invasive spectroscopic technique, namely nuclear magnetic resonance (NMR), to sensitively and non-destructively detect the early stages of biofouling in spiral wound membrane modules. Specifically we consider the use of Earth's field NMR (EF NMR) which offers a comparatively cheap, mobile and noninvasive measurement. We explore the sensitivity of various readily accessible EF NMR parameters (signal relaxation values $T_{1}$ and $T_{2}$ as well as suitably modified total NMR signal) to the extent of biofouling. We also consider the ability for such measurements to be performed under operational conditions (i.e. with flow through the module) as well as the sensitivity of the measurements to the relative location of the EF NMR apparatus along the spiral wound RO membrane module length. 


\section{Background}

\subsection{Relevant Nuclear Magnetic Resonance (NMR) Theory}

Nuclear magnetic resonance (NMR) is a well-known phenomenon in which the magnetic moment of NMR active nuclei (e.g. ${ }^{1} \mathrm{H}$ ) can be analysed using electromagnetic (radio frequency (r.f.)) pulses and applied magnetic fields. Information on the basic principles of NMR can be found elsewhere [28] while useful sources for understanding NMR under flow conditions can be found in Callaghan's texts on magnetic resonance microscopy [29] and transport measurements [30]. In this section we will briefly describe some basic features of NMR, relevant to our measurements.

When a substance containing NMR active nuclei (exclusively ${ }^{1} \mathrm{H}$ in the work conducted here) is placed in a static magnetic field $\left(\boldsymbol{B}_{0}\right)$ the bulk magnetization $(\boldsymbol{M})$ of the substance varies with time [31] as follows:

$$
M_{Z}=M_{Z, 0}\left(1-e^{-t / T_{1}}\right)
$$

where $M_{\mathrm{Z}}$ is the magnitude of the magnetization along the direction $(Z)$ of the net magnetic field vector, $M_{\mathrm{Z}, 0}$ is the magnetization at time zero and $t$ is time. The magnetization $(\boldsymbol{M})$ is proportional to the ${ }^{1} \mathrm{H}$ density in the sample and the static magnetic field strength as follows: $\boldsymbol{M}_{0} \propto \boldsymbol{B}_{0}{ }^{7 / 4}$ [32]. The spin-lattice relaxation time $\left(T_{1}\right)$ characterises the time it takes the system to reach thermal equilibrium, i.e. for the net magnetization vector $\left(M_{\mathrm{Z}}\right)$ to reach $M_{\mathrm{Z}, 0}$ after the sample is placed within magnetic field $\boldsymbol{B}_{0}$. The NMR signal is also characterised by the spinspin relaxation time $\left(T_{2}\right)$ which characterises the loss of signal phase coherence, i.e. the time it takes the NMR signal in the transverse plane (X-Y) to decay towards zero, following radio frequency (r.f.) excitation and can be described by,

$$
M_{x, y}=M_{x, y, 0} e^{-t / T_{2}}
$$

where $M_{\mathrm{x}, \mathrm{y}}$ is the magnitude of the magnetization along the transverse plane $(X-Y)$ relative to the longitudinal direction $(Z)$ of the net magnetic field vector, $M_{\mathrm{x}, \mathrm{y}, 0}$ is the magnetization at time zero. $T_{1}$ and $T_{2}$ are material properties and can be used to distinguish different phases, e.g. biofilm matrix and bulk fluid in our case. It has been observed by multiple researchers (e.g. [33-36]) that the $T_{1}$ and $T_{2}$ relaxation times for NMR signal from water in a biofilm matrix are up to an order of magnitude lower than that of the bulk water phase. 
Measured values of $T_{1}$ and $T_{2}$ are also however (erroneously in the intended application here) influenced by flow, predominately flow into and out of the measurement volume (defined as the regions where r.f. excitation occurs) during the acquisition sequence. This can be approximated as follows [37]:

$$
\frac{1}{T_{1 f \text { or } 2 f}} \approx \frac{1}{T_{1 s \text { or } 2 s}}+\frac{U}{l_{d}}
$$

where $T_{(1 \mathrm{f} \text { or 2f })}$ is the relevant relaxation time of flowing water, $T_{(1 \mathrm{~s} \text { or 2s) }}$ is the relaxation time of stationary water, $U$ is the fluid velocity and $l_{\mathrm{d}}$ is the length of the excited region (approximately the length of the r.f. coil employed for NMR signal excitation). The effect summarised by eq. (3) is obviously complicated when the sample being measured contains a distribution of flow rates or velocities.

\subsection{NMR and Biofilms}

The use of NMR to detect biofilms has a long history. Lewandowski et al. [38] showed that the $T_{1}$ relaxation time of flowing water in a bioreactor will decrease with the presence of biofilm. Hoskins et al. [39] measured the $T_{1}$ and $T_{2}$ relaxation times of water in a packed bed reactor and observed $T_{1}$ and $T_{2}$ relaxation times decreasing in the presence of biofilms. Seymour et al. [40] measured the effect of biofilm growth in a porous medium and observed anomalous transport dynamics using NMR displacement propagator experiments. Graf von der Schulenburg et al. [41] used NMR imaging and velocity imaging techniques to demonstrate that it is a suitable technique for detecting stagnant zones in a reverse osmosis membrane module caused by biofouling. Creber et al. [22] used NMR to study biofouling in a MFS and observed a decrease in $T_{2}$ relaxation time with increased biofilm growth. Vogt et al. [36] used NMR correlation techniques to observe the effects of changing $T_{2}$ time and changing flow field. These previous NMR studies of biofouling have demonstrated some of the detection capabilities of NMR; however these NMR tests have typically been made using relatively small samples and large magnetic fields (generated using superconducting magnets) on the order of a few Tesla [42].

In terms of the application of comparatively low magnetic field NMR measurements (employing permanent magnets) to the study of membranes, biofilms and biofouling, Sanderlin et al. [43] recently used a low-field $\left({ }^{1} \mathrm{H}\right.$ resonance frequency of $\left.280 \mathrm{kHz}\right) \mathrm{NMR}$ well-logging instrument in a laboratory setting to show a reduction in $T_{2}$ caused by biofouling. 
Yang et al. [44] demonstrated the usefulness of a comparatively low-field bench top NMR $\left({ }^{1} \mathrm{H}\right.$ resonance frequency of $12.9 \mathrm{MHz}$ ) apparatus in the investigation of hollow fibre membrane modules as employed in membrane distillation processes in desalination. Here we consider the use of the Earth's magnetic field, which dispenses with the need for a strong homogeneous magnet for signal detection; this is significantly cheaper and enables a portable comparatively easy to handle system.

\section{Materials and Methodology}

\section{NMR Methods Employed}

Measurements were performed using a Terranova-MRI (Magnetic Resonance Imaging) Earth's field NMR instrument purchased from Magritek, New Zealand. A photo of this instrument is shown in Fig. 1(a). This instrument enhances the NMR signal using a coarse electromagnet ( $B_{\text {polarising: }} 18.8 \mathrm{mT}$ ) as a pre-polariser, and then detects at the local earth's magnetic field $\left(52 \mu \mathrm{T}\right.$ with $B_{\text {polarising }}$ turned off) which corresponds to a ${ }^{1} \mathrm{H}$ (Larmor) resonance frequency of $2240 \mathrm{~Hz}$ which is detected by a solenoid r.f. coil of an effective internal diameter (i.d.) of $76 \mathrm{~mm}$. Using the pre-polarisation coil, it is possible to substantially increase the signal to noise ratio (SNR) [45] of the detected NMR signal. This instrument has previously been employed to determine the mean droplet size of various water in oil emulsions [46] as well as included into a novel flow meter [47]. The RO membrane module employed is readily incorporated into the EF NMR apparatus as shown in Fig. 1(b).

The following NMR measurements were performed:

- $\quad$ To measure the total NMR signal $(S)$, a spin echo pulse sequence was employed, the timing diagram of which is shown in Fig. 2(a). The tau waiting time was increased such that the signal detected was only from the stationary fluid, which is discussed in more detail below. $B_{\text {polarising }}$ was applied for $4 \mathrm{~s}$.

- $\quad$ To measure the $T_{2}$ relaxation time, a Carr-Purcell-Meiboom-Gill (CPMG) pulse sequence was employed - see Fig. 2(b) for the relevant timing diagram. The data is fitted with eq. (2). B Bolarising was applied for $4 \mathrm{~s}$ and a tau value of $100 \mathrm{~ms}$ was used.

- $\quad$ To measure the $T_{1}$ relaxation time, the pulse sequence or timing diagram schematically shown in Fig. 2(c) was used. Here the NMR signal $(S)$ is detected as a function of the time 
duration $(t)$ following a $4 \mathrm{~s}$ application of $B_{\text {polarising }}$ at which point signal excitation and detection occurs. $T_{1}$ can then be determined via application of eq. (4):

$$
S=S_{0} \exp \left(-\frac{t}{T_{1}}\right)
$$

Specific EF NMR parameters used for each type of experiment is listed below:

1) Spin Echo - Polarising current: 6A; polarising duration: 4s; B1 gain: 2.5; 90 pulse duration: 1.1; 180 pulse duration: 2.3 ; echo time: $1000 \mathrm{~ms}$; receiver gain: 2 ; number data points: $16384 ; 180$-acq. delay (ms): 25 ; acquisition time: $0.5 \mathrm{~s}$; repetition time: 10s; number of scans: 4 ; display range: $50 \mathrm{~Hz}$; phase cycling: CYCLOPS.

2) Carr-Purcell-Meiboom-Gill (CPMG) - Polarising current: 6A; polarising duration: 4s; B1 gain: 2.5; 90 pulse duration: 1.1; 180 pulse duration: 2.3; receiver gain: 2; number of echoes: 16; echo time: 200ms; number data points: 16384; dwell time: 200us; number of scans: 16; repetition time: 10s; number of scans: 4; integration width: 20; display range: $100 \mathrm{~Hz}$.

3) T1-Be - Polarising current: 6A; polarising duration: 4s; B1 gain: 2.5; receiver gain: 2; 90 pulse duration: 1.1; pre-90 minimum delay: 0ms; pre-90 delay step size: $200 \mathrm{~ms}$; number of steps: 16; 90-acquisition delay: 25ms; number of data points: 16384 ; acquisition time: $1 \mathrm{~s}$; repetition time: $15 \mathrm{~s}$; number of scans: 4 ; integration width: $50 \mathrm{~Hz}$; display range: $50 \mathrm{~Hz}$.

All NMR relaxation measurements were performed at superficial velocities $(U)$ of $0,0.64$ and $1.28 \mathrm{~cm} / \mathrm{s}$, each experiment was run three times; spin echo experiments were conducted at $U$ of $0,0.64,1.28,1.92$ and $2.56 \mathrm{~cm} / \mathrm{s}$, with each experiment conducted four times. Measurements were performed with the EF NMR r.f. coil and electromagnet (length $=17 \mathrm{~cm}$ ) assembly positioned at the following locations along the RO membrane module axis (total length = $53 \mathrm{~cm}$ ): (i) near the entrance (6 to $23 \mathrm{~cm})$, in the middle (18 to $35 \mathrm{~cm}$, as shown in Fig. 1(b)) and near the end (30 to $47 \mathrm{~cm}$ ) respectively. The central permeate channel of the RO membrane module was filled with water during all measurements.

\subsection{RO Membrane Module and Test Conditions}

Tests were conducted on a commercial $61 \mathrm{~mm}$ diameter spiral wound RO membrane module (purchased from Dow FILMTEC ${ }^{\mathrm{TM}}$ Model XLE-2521, FilmTec Corporation, USA). 
This was snuggly accommodated in a $75 \mathrm{~mm}$ outer diameter PVC pipe housing with the module inlet and outlet connected to the fouling circuit using the end caps indicated in the full fouling circuit shown in Fig. 3. During fouling, the feed flow rate was $120 \mathrm{~L} / \mathrm{day}(U=0.07 \mathrm{~cm} / \mathrm{sec})$, which was dosed with $1 \mathrm{~L} /$ day of nutrient solution (i.e. $16 \mathrm{~g}$ sodium acetate, $3.2 \mathrm{~g}$ sodium nitrate and $1.6 \mathrm{~g}$ sodium phosphate in $1 \mathrm{~L}$ of DI water) to enhance biofouling. Sodium phosphate was dosed to avoid phosphate limitation [48]. Nutrients were added to the fouling circuit using a peristaltic pump (Masterflex L/S, Cole-Parmer Instrument Company, Australia). Mains water monitored with a manual pressure gauge ( $\sim 5 \mathrm{barg})$ was used during the experiments and an activated carbon filter (M Series Carbon Filter AQP-RFM1, Aquaport, Australia) was used to remove contaminants (particularly chlorine) which cause membrane degradation [49]. The feed-channel pressure drop between the module inlet and (usually concentrated solution) outlet was monitored using a high precision differential pressure gauge (Cerabar PMC131, Endress Hauser, Germany) [50]. This fouling procedure was consistent with what we have employed in previous RO membrane module biofouling studies and has been generally applied in research on membrane biofouling [22, 25, 41, 51-54].

Fouling was performed over a collective period of 72 days. The suite of NMR measurements discussed above were performed on the initial membrane prior to fouling, and subsequently at three time points during fouling, hereafter referred to as the three stages of biofouling. The extent of fouling at each successive stage was chosen to be more severe than the previous as indicated by the feed-channel pressure drop. Figure 4 shows this pressure drop evolution with time over the 72 day period and the location of the three fouling stages where the NMR measurement suite was performed. An induction phase is evident in all stages. Following stages 1 and 2, and on completion of the NMR measurements, the membrane was flushed at a high value of $U$ in excess of $10 \mathrm{cms}^{-1}$ until the feed-channel pressure drop was restored to its original value, as is evident in Fig. 4. However the reduction in induction time between successive stages suggests that some residual biofouling remained.

Supplementary X-ray CT images of the final fouled module were also acquired using a Siemens medical CT scanner (SOMATOM Definition AS), and high field magnetic resonance images were acquired of the same module using a Bruker BioSpec 9.4 T scanner.

\section{Results and Discussion}




\subsection{Visualisation of Final Fouled Module}

A three-dimensional (3D) X-ray image of the final fouled RO membrane module after Stage 3 is shown in Fig. 5. Cross-sectional images are also presented, as acquired using both 3D X-ray imaging (which will reflect the distribution of density) and high magnetic field 3D MRI. The membrane module was filled with water during these experiments. The external PVC casing of the module is evident in the X-ray images as are the inlet and outlet fittings. Also evident in Fig. 5 is the presence of glue sealing the ends of the membrane sheets; the EF NMR measurement zones were fortuitously selected so as to avoid these regions. Fig. 6 shows photos of the membrane module following an autopsy - clear visual evidence is presented of the accumulation of biofouling material near the entrance of the module, which was not present in the middle or exit regions of the module. The presence of this fouling material is not immediately evident in either the X-ray or high field MRI images in Fig. 5. It can however be detected based on imaging the distribution of $T_{2}$ values when performing the $3 \mathrm{D}$ high field MRI acquisition. Fig. 7 shows the measured $T_{2}$ distribution maps/images for the entrance and middle regions, along with the corresponding $T_{2}$ probability distributions. Clearly a reduced value of $T_{2}$ is measured in the entry region where biofouling was visually evident, consistent with literature. The high field MRI is able to detect biofouling using $T_{2}$ relaxation times. It is worth highlighting that the quality and resolution of images and data in Fig. 5 and 6 using high field MRI are not readily accessible using EF NMR; nevertheless very useful non-invasive data is able to be detected using EF NMR regards biofouling, as will be subsequently demonstrated.

\subsection{EF NMR Relaxation Measurements}

Fig. 8 shows the evolution in the $T_{1}$ and $T_{2}$ measurements for the three measurement positions along the RO membrane module length (as outlined in Fig. 5 above) for the clean module and as a function of fouling stage. The error bars are the standard deviations produced by multiple repeats of the measurements. These measurements were performed without flow through the module. $T_{1}$, and to a lesser extent $T_{2}$, decreased as fouling progressed distinctly in the inlet region of the module, which is consistent with the observed biofouling in this region discussed above. The effect is much less pronounced for the middle region and outlet regions. Furthermore once the effect of flow $(U \neq 0)$ is introduced (as summarised in Fig. 9) it becomes apparent that a simple $T_{1}$ and $T_{2}$ relaxation time reduction as biofouling progresses is obscured by the effect of flow on the relevant relaxation parameter; at the highest flow rate $(U=1.28$ $\mathrm{cm} / \mathrm{s}$ ) studied, there was no obvious correlation. In addition the effect of flow and the 
contribution of inflow-outflow effects during the measurement results in deviations from the exponential assumption of the $T_{1}$ and $T_{2}$ relaxation time fits. This effect may be de-convolved and quantified but requires detailed knowledge of the flow field $(U)$. A simple robust correlation between the EF NMR relaxation parameters that could be routinely used as an early warning indicator of the onset of biofouling in the RO membrane modules is clearly precluded by the complex effects of flow. Even in the absence of flow, the ability of EF NMR relaxation measurements to detect biofouling requires deployment of the measurement in the vicinity of the fouling along the RO membrane module axis (in this case near the module entry). While useful information is available from the $T_{1}$ and $T_{2}$ relaxation time measurements, due to the complicated relationship between fluid flow distribution and relaxation times and their effects on the measured EF NMR signal, these measurements were found to be less suitable at detecting biofouling under flowing conditions. However, the portable EF NMR derived $T_{1}$ and $T_{2}$ relaxation times are suitable to non-destructively detect the location of biofouling in spiral wound membrane elements in the absence of fluid flow.

\subsection{Spin-Echo Measurements of Total NMR signal}

Fig. 10 shows the measured EF NMR signal as a function of velocity, fouling stage and position along the module length, as acquired using the simple spin-echo pulse sequence shown in Fig. 2(a). The signal intensities are normalised relative to that detected in the absence of any flow or fouling. It has been shown in the literature that biofouling within complex flow structures (e.g. porous media and membranes) results in dramatic transition of the flow-field, characterised by the development of stagnant regions and skeletal rapid flow structure $[22,36$, 41, 55-58]. As tau and $U$ are increased, signal intensity from this skeletal flowing fluid is reduced and eventually eliminated; this essentially occurs when all fluid that has been prepolarised has been flushed out of the module when signal acquisition occurs. This can be approximated as occurring when:

$$
\frac{2 . t a u . U}{\sigma}>L,
$$

where $\sigma$ is the porosity of the membrane/spacer assembly and $L$ is the length of the polarised region. The tau time in Fig. 2(a) was increased (to a value of $500 \mathrm{~ms}$ ) such that for the highest flow rate systematically studied here $(U=2.56 \mathrm{~cm} / \mathrm{s})$, signal was essentially received only from stagnant fluid inside the module; this can be checked by repeating the measurements at a higher flow rate and checking that the signal intensity detected is unaffected (this of course assumes 
the fraction of fluid that is stationary remains constant as velocity increases). Constraints on selecting tau and $U$ in practice will naturally be the prevailing operational velocity and a reduction in SNR as tau is increased due to $T_{2}$ relaxation effects. It is expected that this methodology will be more sensitive at higher velocities such as at typical operational range up to $0.2 \mathrm{~m} / \mathrm{s}$, as the tau values consequently required are shorter.

With reference to Fig. 10, for the un-fouled membrane, the effect of flow is clearly evident as $S / S_{\text {(no flow) }}$ reduces systematically with flow for all three positions. The largest flow rate employed $(U=2.56 \mathrm{~cm} / \mathrm{s})$ corresponds to a plateau in signal and represents the stagnant fluid in the module. This plateau value of $S / S_{\text {(no flow) }}$ is $11 \%$; based on geometric considerations, the contribution from the permeate channel (which was flooded during all EF NMR measurements and which was stationary) is $10 \%$. This indicates that for no fouling the vast majority of the detected signal originated from the permeate channel and that the flow field through the module is homogeneous. Data for $U=2.56 \mathrm{~cm} / \mathrm{s}$ thus acts as a semi-quantitative indicator of stagnant water fraction in the module.

As fouling progresses, what is immediately obvious is that the reduction in $S / S_{\text {(no flow) }}$ with increasing flow rate is gradually eliminated. This reflects the change in internal hydrodynamics within the membrane module. For fouling stages 2 and 3 (Fig. 4), the value of $S / S_{\text {(no flow) }}$ is essentially independent of flow rate; this reflects the portion of the module that is essentially stagnant. The mean EF NMR signal $\left(S / S_{\text {(no flow) }}\right)$ for the inlet, middle and outlet sections of the RO membrane module is respectively $0.54,0.53$ and 0.52 . This means that approximately half the fluid volume of the total module is stagnant, while the other half is available for fluid transport. If we focus on the measurement of $S / S_{\text {(no flow) }}$ for $U=2.56 \mathrm{cms}^{-1}$, which we know in the unfouled state reflects predominately on stagnant fluid, we see a significant increase as fouling progresses. Of equal interest is that this increase is only partially reduced between the inlet (where fouling is visually evident upon autopsy) and the middle and outlet regions. Fouling near the entrance of the spiral wound membrane module significantly disturbed the flow field, as measured with the EF NMR, through the whole spiral membrane module. These results indicate that the total NMR signal from the EF NMR, as reported in Fig. 10 , allows for the early non-destructive detection of biofouling in spiral wound membrane 
elements during cross flow operation in a pressure vessel, and that this measurement can be performed at any position along the module axis.

\subsection{Practical Implications and Further Studies}

\subsubsection{Potential field of EF NMR use}

The mobile EF NMR can be used to non-destructively (i) detect early fouling, as demonstrated here, and (ii) hence also evaluate the efficiency of cleaning directly during the cleaning process. Most likely the EF NMR can also be useful to evaluate the production process of membrane modules via its sensitivity to the internal flow field. The total NMR signal (as measured using a simple spin echo pulse sequence) is suitable for detecting biofouling during cross flow operation, and the sensitivity is improved at linear flow velocities applied in practice. In the absence of fluid flow, the EF NMR $T_{2}$ relaxation time is suitable to non-destructively detect the location of biofouling along the axis of the spiral wound membrane elements. Use of the EF NMR during cleaning will reduce cleaning chemical consumption and down time since the cleaning can be halted when fouling is removed. The cleaning process can also be prolonged or modified in the case of the fouling not being removed.

\subsubsection{Measurement of membrane element fouling in pressure vessels during operation}

Pressure vessels contain in practice up to 8 spiral wound membrane elements in series. These pressure vessels are made of non-metal material (glass fibre). Therefore, it is anticipated that the mobile EF NMR can be used to non-destructively detect fouling in membrane modules while placed in pressure vessels during operation. In this study, linear cross flow velocities of fluid in membrane modules up to $2.56 \mathrm{~cm} / \mathrm{s}$ were used to detect fouling. The detection of accumulated fouling will be better at higher cross flow velocities, indicating that fouling detection at practice operational conditions (e.g. $0.2 \mathrm{~m} / \mathrm{s}$ ) will provide even more sensitive and enable early fouling detection. These pressure vessels contain metal connections at their beginning and end for the feed, concentrate and permeate water flows and connection to the frame. These would not be directly in the measurement field of view, however they would prevent ready placement of the EF NMR system on the pressure vessel during operations. An additional complication is that the modules in industry practice are typically 4 or 8 inches in diameter. 


\subsubsection{Further research}

Consequently, the development of an EF NMR system for larger diameter membrane elements is currently being considered, as is reconfiguration of the polarising coil such that it is able to be clamped on to the pressure vessel during operation [59], in the form of a Cuff. We note that there is no obvious physical limitation preventing scale-up of the apparatus to these larger dimensions. In addition possibilities for non-destructive discrimination between fouling types: particulate, biofouling and inorganic are being explored. This features a composition of the current demonstrated simple signal measurement that correlates with the extent of fluid stagnation, with measurements of NMR signal relaxation and diffusion/transport. Other significant challenges in terms of the practical application of EF NMR to these modules include: (i) the module axis needs to be perpendicular to the Earth's magnetic field for optimal SNR and would deliver no signal if parallel and (ii) in practice flow will occur in the central permeate channel. (i) could be eliminated by detection in the presence of a weak magnet. Regarding (ii), this needs to be researched further as to the effect of flow in the central permeate channel on the NMR signal detected; if at a sufficiently rapid velocity, it would have no effect and actually increase the sensitivity of the instrument relative to the data shown in Fig. 10. We will also in future look to benchmark our approach more widely against other potential nondestructive (and preferably truly non-invasive) options for early fouling detection.

\section{Conclusions}

This work has shown the use of a relatively simple and robust Earth's field (EF) NMR based measurement technique for the early non-destructive detection of fouling within a spiral wound reverse osmosis and nanofiltration membrane modules. This is based on measuring the total EF NMR signal under flow conditions, with increasing NMR signal detected due to fluid stagnation, which correlates with biofouling within the reverse osmosis membrane module. The proposed non-destructive and direct measurement technique can be performed under operational conditions and at any location along the membrane module or, in practice the pressure vessel. The proposed technique is suitable for early fouling detection as the time to evaluate the presence/absence of biofouling is fast (i.e. on the order of seconds). There are no predicted issues with applying this technique at higher operational pressures, and whilst the 
above study has focussed on biofouling, it could equally be applied to other fouling sources which change the flow field inside the membrane module.

\section{Acknowledgements:}

The authors acknowledge funding from ARC LIEF LE110100189 and the UWA ECM Research Development Grant. The authors acknowledge the contributions of Mr. Wiktor Bilinski, Mr. Samuel Clement and Mr. Patrick Jennings. The authors acknowledge the facilities, and the scientific and technical assistance of the National Imaging Facility at the Centre for Microscopy, Characterisation and Analysis, University of Western Australia. Measurements were performed using Siemens medical CT scanner courtesy of the National Geosequestration Laboratory (NGL). NGL is a collaboration between CSIRO, The University of Western Australia and Curtin University, supported by the Australian Federal Government. 


\section{References}

[1] UNWater.org, World Water Day, in, http://www.unwater.org/worldwaterday/campaignmaterials/documents-and-information-resources/en/, 2014.

[2] L.F. Greenlee, D.F. Lawler, B.D. Freeman, B. Marrot, P. Moulin, Reverse osmosis desalination: water sources, technology, and today's challenges, Water Research, 43 (2009) 2317-2348.

[3] W. Lawler, Z. Bradford-Hartke, M.J. Cran, M. Duke, G. Leslie, B.P. Ladewig, P. Le-Clech, Towards new opportunities for reuse, recycling and disposal of used reverse osmosis membranes, Desalination, 299 (2012) 103-112.

[4] K. Tasaka, T. Katsura, H. Iwahori, Y. Kamiyama, Analysis of RO elements operated at more than 80 plants in Japan, Desalination, 96 (1994) 259-272.

[5] H.F. Ridgway, H.-C. Flemming, Membrane biofouling in water treatment membrane processes, Journal of Membrane Science, 175 (1996) 61-73.

[6] E.M. Vrijenhoek, S. Hong, M. Elimelech, Influence of membrane surface properties on initial rate of colloidal fouling of reverse osmosis and nanofiltration membranes, Journal of Membrane Science, 188 (2001) 115-128.

[7] M.A. Shannon, P.W. Bohn, M. Elimelech, J.G. Georgiadis, B.J. Marinas, A.M. Mayes, Science and technology for water purification in the coming decades, Nature, 452 (2008) 301-310.

[8] J.S. Vrouwenvelder, S.A. Manolarakis, J.P. Van der Hoek, J.A.M. Van Paassen, W.G.J. Van der Meer, J.M.C. Van Agtmaal, H.D.M. Prummel, J.C. Kruithof, M.C.M. Van Loosdrecht, Quantitative biofouling diagnosis in full scale nanofiltration and reverse osmosis installations, Water Research, 42 (2008) 4856-4868.

[9] H.F. Ridgway, Biological Fouling of Seperation Membranes Used in Water Treatment Applications, AWWA Research Foundation, 2003.

[10] J.S. Vrouwenvelder, M.C.M. Van Loosdrecht, J.C. Kruithof, Early warning of biofouling in spiral wound nanofiltration and reverse osmosis membranes, Desalination, 265 (2011) 206-212.

[11] J.S. Vrouwenvelder, J.A.M. Van Paassen, L.P. Wessels, A.F. Van Dam, S.M. Bakker, The membrane fouling simulator: a practical tool for fouling prediction and control, Journal of Membrane Science, 281 (2006) 316-324.

[12] M.F.A. Goosen, S.S. Sablani, H. Al-Hinai, S. Al-Obeidani, R. Al-Belushi, D. Jackson, Fouling of reverse osmosis and ultrafiltration membranes: a critical review, Separation Science and Technology, 39 (2005) 2261-2297.

[13] R.A. Al-Juboori, T. Yusaf, Biofouling in RO system: mechanisms, monitoring and controlling, Desalination, 302 (2012) 1-23.

[14] H.-C. Flemming, G. Schaule, T. Griebe, J. Schmitt, A. Tamachkiarowa, Biofouling-the Achilles heel of membrane processes, Desalination, 113 (1997) 215-225.

[15] J.W. Costerton, Z. Lewandowski, D.E. Caldwell, D.R. Korber, H.M. Lappinscott, Microbial biofilms, Annual Review of Microbiology, 49 (1995) 711-745.

[16] W. Guo, H.-H. Ngo, J. Li, A mini-review on membrane fouling, Bioresource Technology, 122 (2012) 27-34.

[17] A. Matin, Z. Khan, S.M.J. Zaidi, M.C. Boyce, Biofouling in reverse osmosis membranes for seawater desalination: phenomena and prevention, Desalination, 281 (2011) 1-16.

[18] J.S. Vrouwenvelder, M.C.M. Van Loosdrecht, J.C. Kruithof, A novel scenario for biofouling control of spiral wound membrane systems, Water Research, 45 (2011) 3890-3898.

[19] T.R.R. Pintelon, C. Picioreanu, M.C.M. van Loosdrecht, M.L. Johns, The effect of biofilm permeability on bio-clogging of porous media, Biotechnology and Bioengineering, 109 (2012) 10311042.

[20] H.-C. Flemming, Reverse osmosis membrane biofouling, Experimental Thermal and Fluid Science, 14 (1997) 382-391.

[21] B. Manz, F. Volke, D. Goll, H. Horn, Investigation of biofilm structure, flow patterns and detachment with magnetic resonance imaging, Water Science \& Technology, 52 (2005) 1-6. 
[22] S.A. Creber, J.S. Vrouwenvelder, M.C.M. Van Loosdrecht, M.L. Johns, Chemical cleaning of biofouling in reverse osmosis membranes evaluated using magnetic resonance imaging, Journal of Membrane Science, 362 (2010) 202-210.

[23] J.S. Vrouwenvelder, J. Buiter, M. Riviere, W.G.J. Van der Meer, M.C.M. Van Loosdrecht, J.C. Kruithof, Impact of flow regime on pressure drop increase and biomass accumulation and morphology in membrane systems, Water research, 44 (2010) 689-702.

[24] J.S. Vrouwenvelder, C.W.G.J. Hinrichs, W.G.J. Van der Meer, M.C.M. Van Loosdrecht, J.C. Kruithof, Pressure drop increase by biofilm accumulation in spiral wound RO and NF membrane systems: role of substrate concentration, flow velocity, substrate load and flow direction, Biofouling, 25 (2009) 543-555.

[25] J.S. Vrouwenvelder, D.A. Graf Von Der Schulenburg, J.C. Kruithof, M.L. Johns, M.C.M. Van Loosdrecht, Biofouling of spiral-wound nanofiltration and reverse osmosis membranes: a feed spacer problem, Water Research, 43 (2009) 583-594.

[26] Y. Marselina, P. Le-Clech, R.M. Stuetz, V. Chen, Characterisation of membrane fouling deposition and removal by direct observation technique, Journal of Membrane Science, 341 (2009) 163-171.

[27] T. Chilcott, A. Antony, H. Coster, G. Leslie, In situ characterization of fouling in reverse osmosis membranes using electrical impedance spectroscopy, in: Journal of Physics: Conference Series, IOP Publishing, 2013, pp. 012089.

[28] A. Abragam, The principles of nuclear magnetism, Clarendon Press, Oxford, 1961.

[29] P.T. Callaghan, Principles of NMR microscopy, Clarendon Press, Oxford, 1991.

[30] P.T. Callaghan, Translational dynamics and magnetic resonance: principles of pulsed gradient spin echo NMR, Oxford University Press, 2011.

[31] J.M. Pendlebury, K. Smith, P. Unsworth, G.L. Greene, W. Mampe, Precision field averaging NMR magnetometer for low and high fields, using flowing water, Review of Scientific Instruments, 50 (1979) 535-540.

[32] E. Fukushima, Nuclear magnetic resonance as a tool to study flow, Annual Review of Fluid Mechanics, 31 (1999) 95-123.

[33] E.E. Beuling, D. van Dusschoten, P. Lens, J.C. van den Heuvel, H. Van As, S.P.P. Ottengraf, Characterization of the diffusive properties of biofilms using pulsed field gradient-nuclear magnetic resonance, Biotechnology and Bioengineering, 60 (1998) 283-291.

[34] R.S. Renslow, P.D. Majors, J.S. McLean, J.K. Fredrickson, B. Ahmed, H. Beyenal, In Situ Effective Diffusion Coefficient Profiles in Live Biofilms Using Pulsed-Field Gradient Nuclear Magnetic Resonance, Biotechnology and Bioengineering, 106 (2010) 928-937.

[35] S.L. Codd, S.J. Vogt, J.A. Hornemann, A.J. Phillips, J.E. Maneval, K.R. Romanenko, L. Hansen, A.B. Cunningham, J.D. Seymour, NMR relaxation measurements of biofouling in model and geological porous media, Organic Geochemistry, 42 (2011) 965-971.

[36] S.J. Vogt, A.B. Sanderlin, J.D. Seymour, S.L. Codd, Permeability of a growing biofilm in a porous media fluid flow analyzed by magnetic resonance displacement-relaxation correlations,

Biotechnology and Bioengineering, 110 (2013) 1366-1375.

[37] E. Mueller, M. Deimling, E.R. Reinhardt, Quantification of pulsatile flow in MRI by an analysis of T2 changes in ECG-gated multiecho experiments, Magnetic Resonance in Medicine, 3 (1986) 331335.

[38] Z. Lewandowski, S.A. Altobelli, P.D. Majors, E. Fukushima, NMR imaging of hydrodynamics near microbially colonized surfaces, Water Science \& Technology, 26 (1992) 577-584.

[39] B.C. Hoskins, L. Fevang, P.D. Majors, M.M. Sharma, G. Georgiou, Selective imaging of biofilms in porous media by NMR relaxation, Journal of Magnetic Resonance, 139 (1999) 67-73.

[40] J.D. Seymour, J.P. Gage, S.L. Codd, R. Gerlach, Anomalous fluid transport in porous media induced by biofilm growth, Physical Review Letters, 93 (2004) 198103.

[41] D.A. Graf von der Schulenburg, J.S. Vrouwenvelder, S.A. Creber, M.C.M. Van Loosdrecht, M.L. Johns, Nuclear magnetic resonance microscopy studies of membrane biofouling, Journal of Membrane Science, 323 (2008) 37-44. 
[42] B. Blümich, F. Casanova, S. Appelt, NMR at low magnetic fields, Chemical Physics Letters, 477 (2009) 231-240.

[43] A.B. Sanderlin, S.J. Vogt, E. Grunewald, B.A. Bergin, S.L. Codd, Biofilm detection in natural unconsolidated porous media using a low-field magnetic resonance system, Environmental Science \& Technology, 47 (2013) 987-992.

[44] X. Yang, E.O. Fridjonsson, M.L. Johns, R. Wang, A.G. Fane, A non-invasive study of flow dynamics in membrane distillation hollow fiber modules using low-field nuclear magnetic resonance imaging (MRI), Journal of Membrane Science, 451 (2014) 46-54.

[45] G.J. Béné, Nuclear magnetism of liquid systems in the Earth field range, Physics Reports, 58 (1980) 213-267.

[46] E.O. Fridjonsson, L.S. Flux, M.L. Johns, Determination of mean droplet sizes of water-in-oil emulsions using an Earth's field NMR instrument, Journal of Magnetic Resonance, 221 (2012) 97102.

[47] E.O. Fridjonsson, P.L. Stanwix, M.L. Johns, Earth's Field NMR Flow Meter: Preliminary Quantitative Measurements, Journal of Magnetic Resonance, (2014).

[48] J.S. Vrouwenvelder, F. Beyer, K. Dahmani, N. Hasan, G. Galjaard, J.C. Kruithof, M.C.M. Van Loosdrecht, Phosphate limitation to control biofouling, Water Research, 44 (2010) 3454-3466.

[49] A. Simon, L.D. Nghiem, P. Le-Clech, S.J. Khan, J.E. Drewes, Effects of membrane degradation on the removal of pharmaceutically active compounds (PhACs) by NF/RO filtration processes, Journal of Membrane Science, 340 (2009) 16-25.

[50] J.S. Vrouwenvelder, J.A.M. Van Paassen, J.C. Kruithof, M.C.M. Van Loosdrecht, Sensitive pressure drop measurements of individual lead membrane elements for accurate early biofouling detection, Journal of Membrane Science, 338 (2009) 92-99.

[51] J.W.N.M. Kappelhof, H. Vrouwenvelder, M. Schaap, J.C. Kruithof, D. Van Der Kooij, J. Schippers, An in situ biofouling monitor for membrane systems, Water Supply, 3 (2003) 205-210.

[52] S.A. Creber, T.R.R. Pintelon, D.A.W. Graf von der Schulenburg, J.S. Vrouwenvelder, M.C.M. Van Loosdrecht, M.L. Johns, Magnetic resonance imaging and 3D simulation studies of biofilm accumulation and cleaning on reverse osmosis membranes, Food and Bioproducts Processing, 88 (2010) 401-408.

[53] D.J. Miller, P.A. Araujo, P.B. Correia, M.M. Ramsey, J.C. Kruithof, M.C.M. van Loosdrecht, B.D. Freeman, D.R. Paul, M. Whiteley, J.S. Vrouwenvelder, Short-term adhesion and long-term biofouling testing of polydopamine and poly (ethylene glycol) surface modifications of membranes and feed spacers for biofouling control, Water research, 46 (2012) 3737-3753.

[54] C. Dreszer, J.S. Vrouwenvelder, A.H. Paulitsch-Fuchs, A. Zwijnenburg, J.C. Kruithof, H.-C. Flemming, Hydraulic resistance of biofilms, Journal of Membrane Science, 429 (2013) 436-447. [55] R. Sharp, P. Stoodley, M. Adgie, R. Gerlach, A. Cunningham, Visualization and characterization of dynamic patterns of flow, growth and activity of biofilms growing in porous media, Water Science \& Technology, 52 (2005) 85-90.

[56] M. Thullner, L. Mauclaire, M.H. Schroth, W. Kinzelbach, J. Zeyer, Interaction between water flow and spatial distribution of microbial growth in a two-dimensional flow field in saturated porous media, Journal of Contaminant Hydrology, 58 (2002) 169-189.

[57] D.-S. Kim, H.S. Fogler, Biomass evolution in porous media and its effects on permeability under starvation conditions, Biotechnology and Bioengineering, 69 (2000) 47-56.

[58] J.D. Seymour, J.P. Gage, S.L. Codd, R. Gerlach, Magnetic resonance microscopy of biofouling induced scale dependent transport in porous media, Advances in Water Resources, 30 (2007) 14081420.

[59] C.W. Windt, H. Soltner, D. van Dusschoten, P. Blümler, A portable Halbach magnet that can be opened and closed without force: the NMR-CUFF, Journal of Magnetic Resonance, 208 (2011) 27-33. 


\section{Figure Captions}

Fig. 1. (a) Photograph of the Earth Field (EF) Nuclear Magnetic Resonance (NMR) instrument components (Laptop computer, Terranova MRI spectrometer \& EF NMR probe); (b) Image of the EF NMR probe showing its dimensions; shown inserted into the probe is the spiral wound RO membrane module housing (pressure vessel).

Fig. 2. Timing diagrams for (a) spin echo, (b) $T_{2}$ measurements - Carr-Purcell-Meiboom-Gill (CPMG) (looped $180^{\circ}$ pulses $n$ times) and (c) $T_{1}$ measurements, where $\boldsymbol{t}$ is a variable wait time.

Fig. 3. (a) RO membrane module, pressure vessel and end caps, (b) schematic of the experimental flow loop setup.

Fig. 4. Feed channel pressure drop during fouling stages; EF NMR experiments are conducted at the end of each fouling stage (indicated by arrows).

Fig. 5. CT scan of the reverse osmosis (RO) membrane module, with the location of the entrance, middle and exit regions shown. Insert pictures shows examples of high field MRI and x-ray images obtained. Also indicate are the RO membrane end caps and "glued" regions. CT scan parameters: $120 \mathrm{kV} / 500 \mathrm{mAs}, 0.5 \mathrm{~mm}$ resolution. MRI parameters: slice thickness $1 \mathrm{~mm}, 1024$ x 1024 pixels, field of view $60 \mathrm{~mm} \times 60 \mathrm{~mm}$, in-plane resolution $59 \mu \mathrm{m} \times 59 \mu \mathrm{m}$. The probability distributions have been normalised such that each equals unity (i.e. $\sum P\left(T_{2}\right)=1$ ), this is for ease of comparison.

Fig. 6. Photographs of membrane and feed spacer at the membrane module inlet and outlet sides after RO membrane module dissection. A significant amount of biomass was found at the RO membrane module inlet, compared with limited amount of biomass at the outlet.

Fig. 7. $T_{2}$ maps obtained at (a) entrance and (b) middle region of the fouled RO membrane module, with the mean $T_{2}$ value shown; (c) shows the $T_{2}$ distributions obtained from these $T_{2}$ maps; measured using the high field MRI instrument. MRI parameters: Echo time $\left(T_{\mathrm{E}}\right)=23.8 \mathrm{~ms}, 10$ echo images acquired, slice thickness $=1 \mathrm{~mm}, 1024 \times 1024$ pixels, field of view $60 \mathrm{~mm} \times 60 \mathrm{~mm}$, in-plane resolution $59 \mu \mathrm{m} \times 59 \mu \mathrm{m}$. 
Fig. 8. $T_{1}$ and $T_{2}$ relaxation time of the fluid at the membrane module inlet, middle and outlet regions, at different stages of biofouling (no fouling, stage 1, stage 2 and stage 3 ) during no flow conditions; measured using EF NMR instrument.

Fig. 9. $T_{1}$ and $T_{2}$ relaxation times at three different flow rates $(U=0,0.64$ and $1.28 \mathrm{~cm} / \mathrm{s})$, at different stages of biofouling (no fouling, stage 1, stage 2 and stage 3); measured using EF NMR instrument.

Fig. 10. Normalised total NMR signal measured with the EF NMR at different stages of biofouling (no fouling, stage 1 , stage 2 and stage 3$)$ for increasing mean flow rates $(0.64 \mathrm{~cm} / \mathrm{s}, 1.28 \mathrm{~cm} / \mathrm{s}, 1.92 \mathrm{~cm} / \mathrm{s}$ and $2.56 \mathrm{~cm} / \mathrm{s}$ ) non-destructively determined at the spiral wound RO membrane module inlet, middle and outlet regions. 
Figure 1

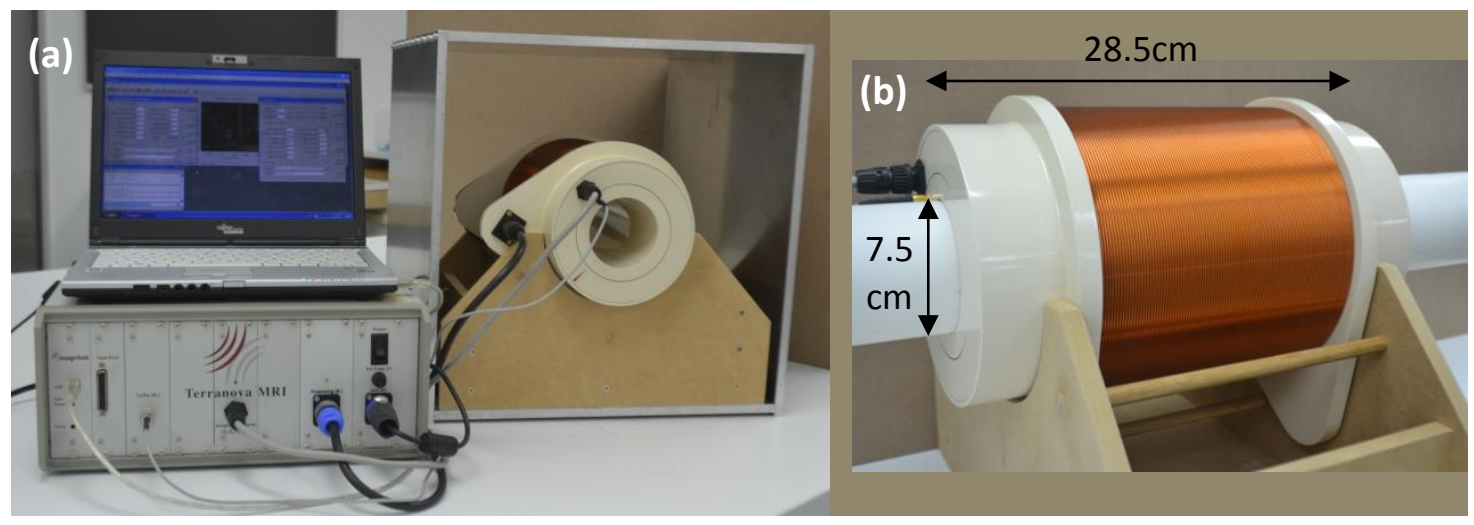


Figure 2

(a)
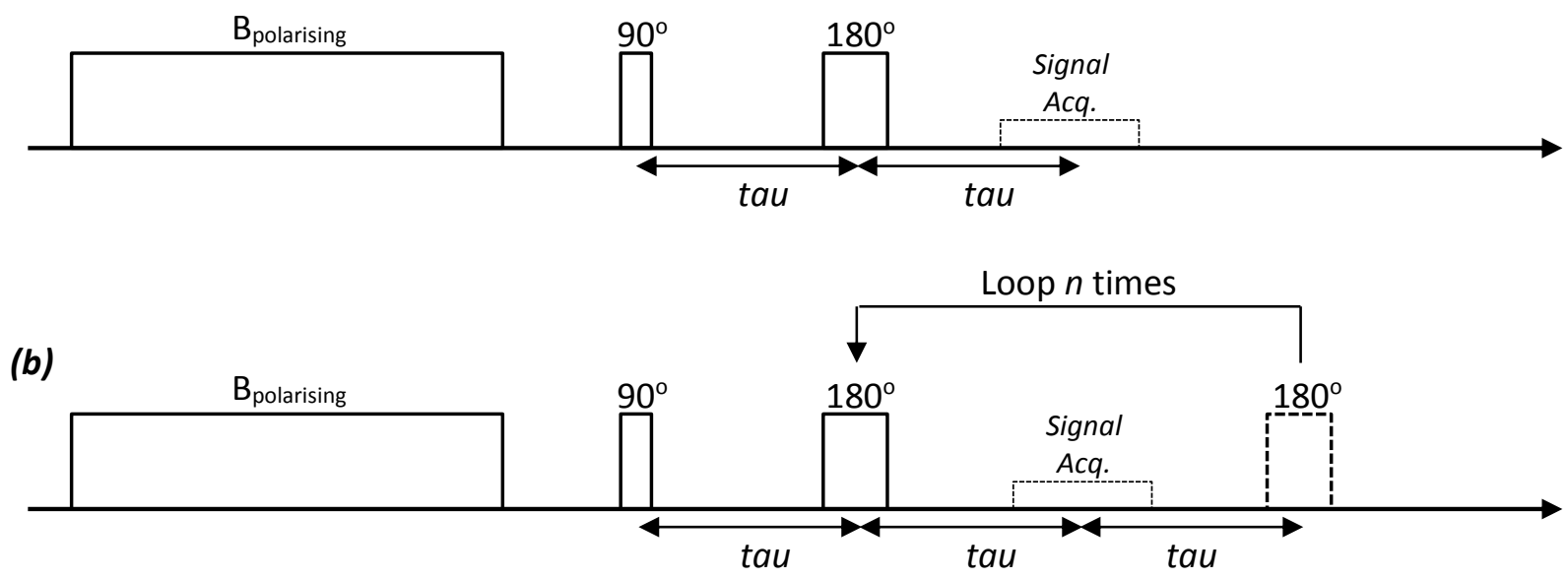

(c)

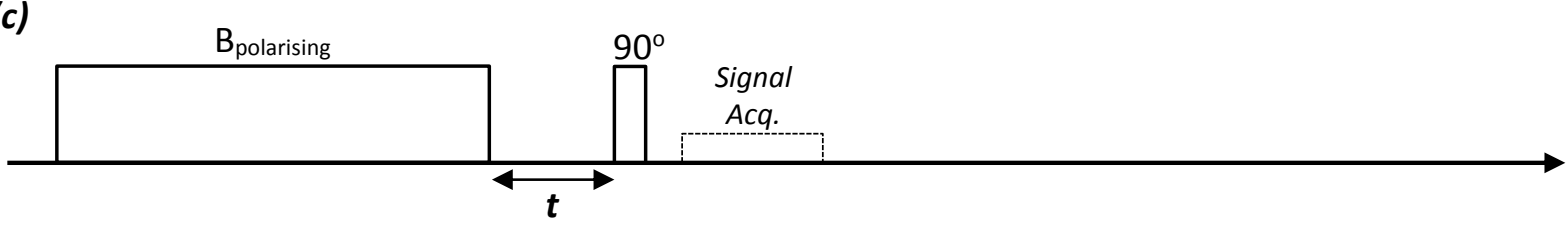


Figure 3

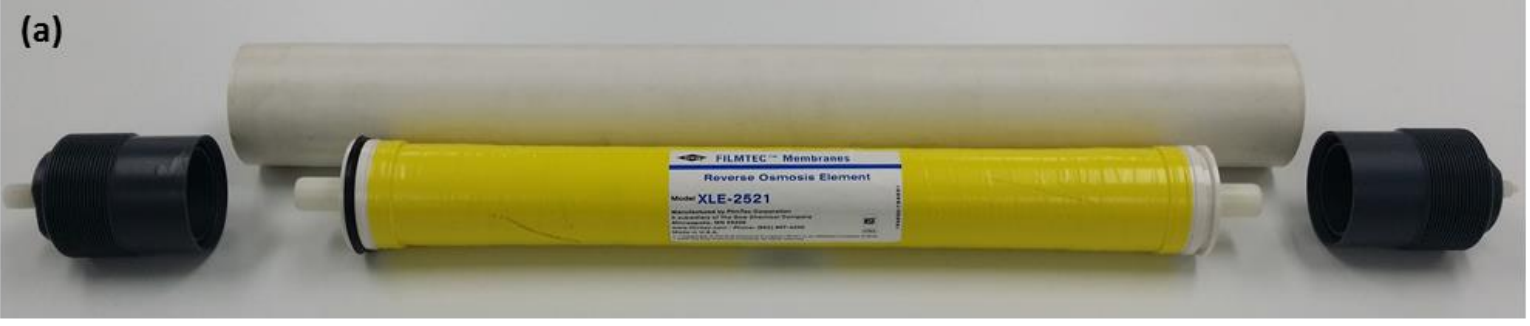

(b)

Differential Pressure Gauge

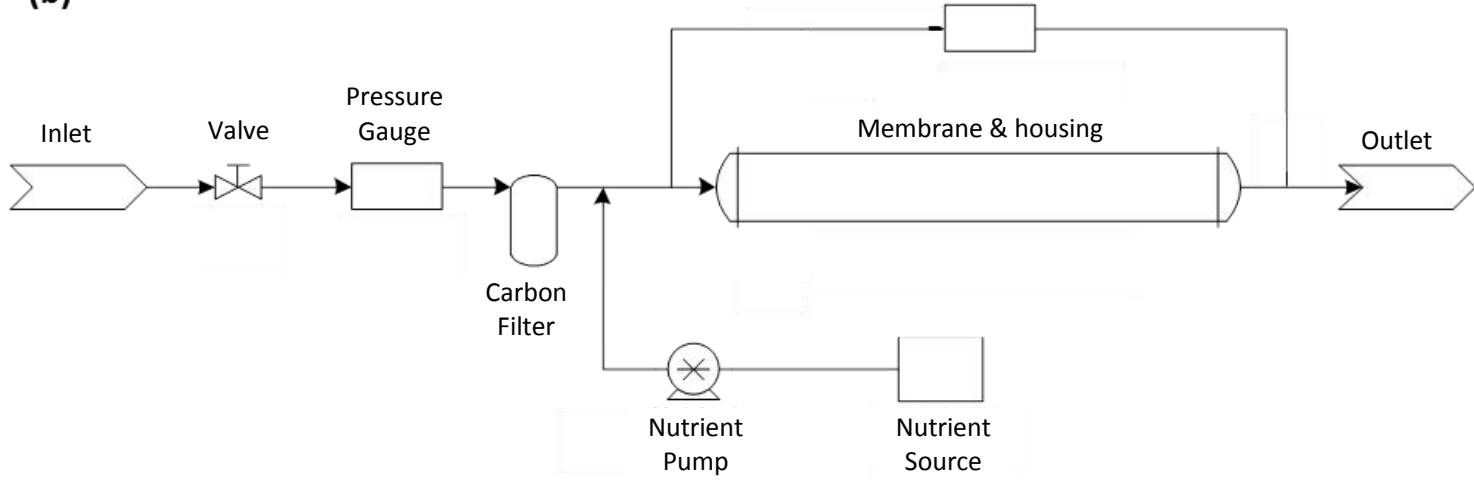


Figure 4

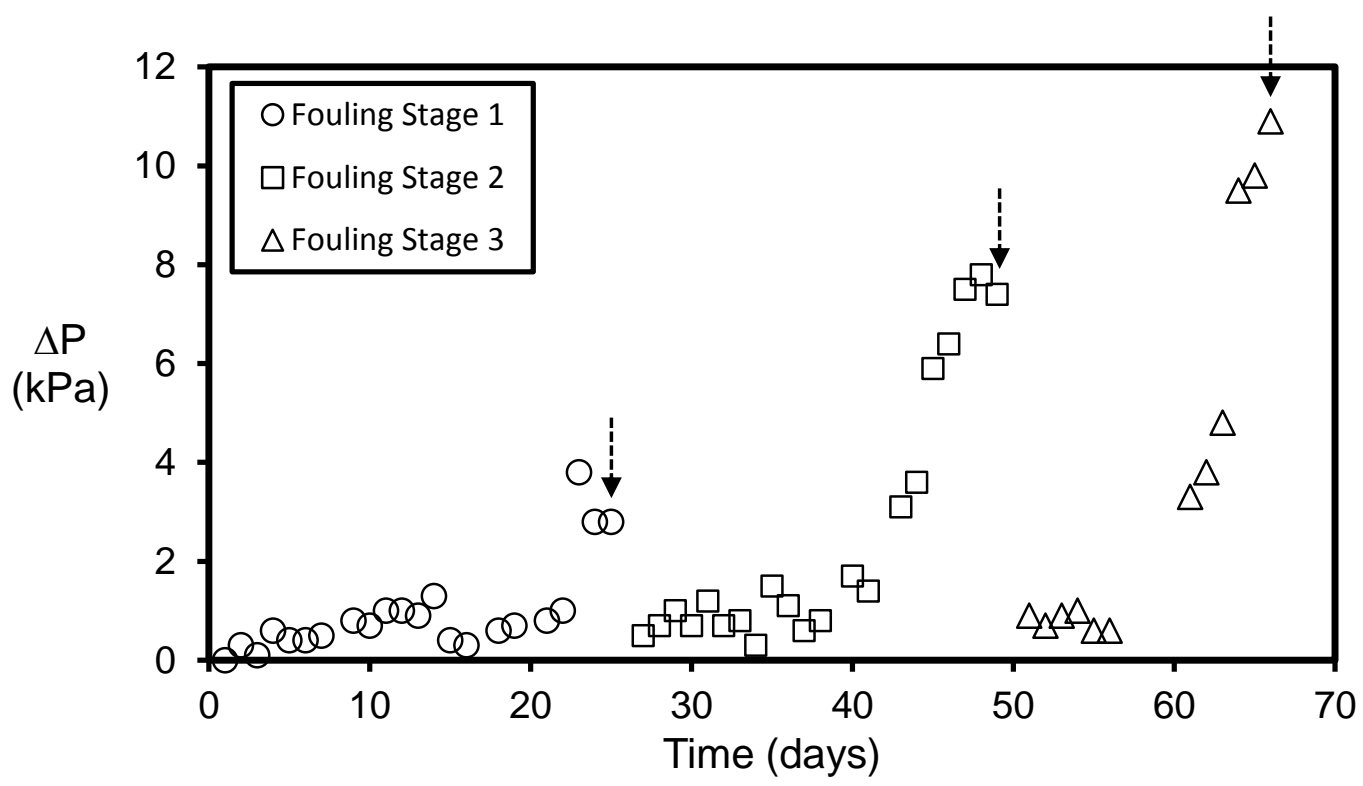


25

Figure 5

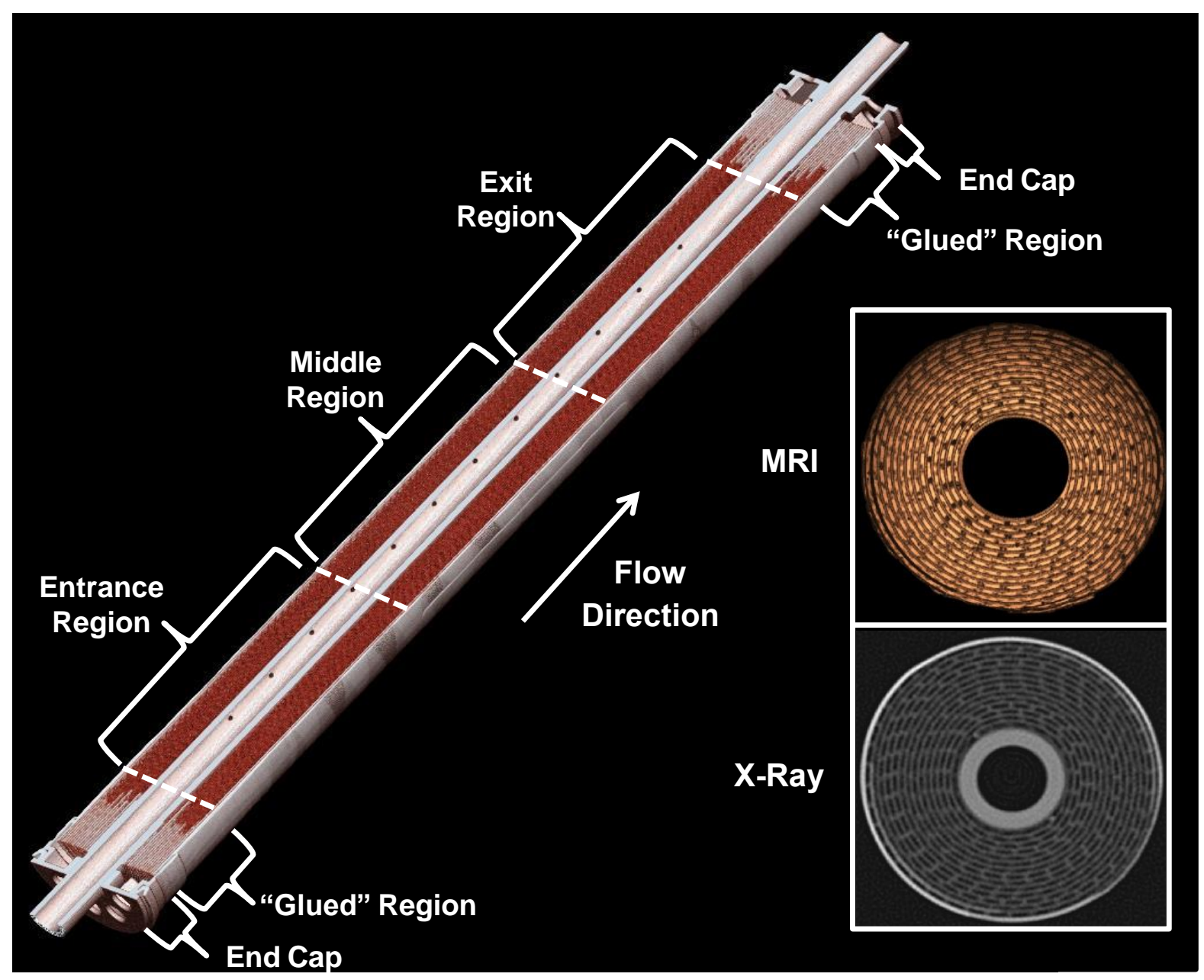


Figure 6

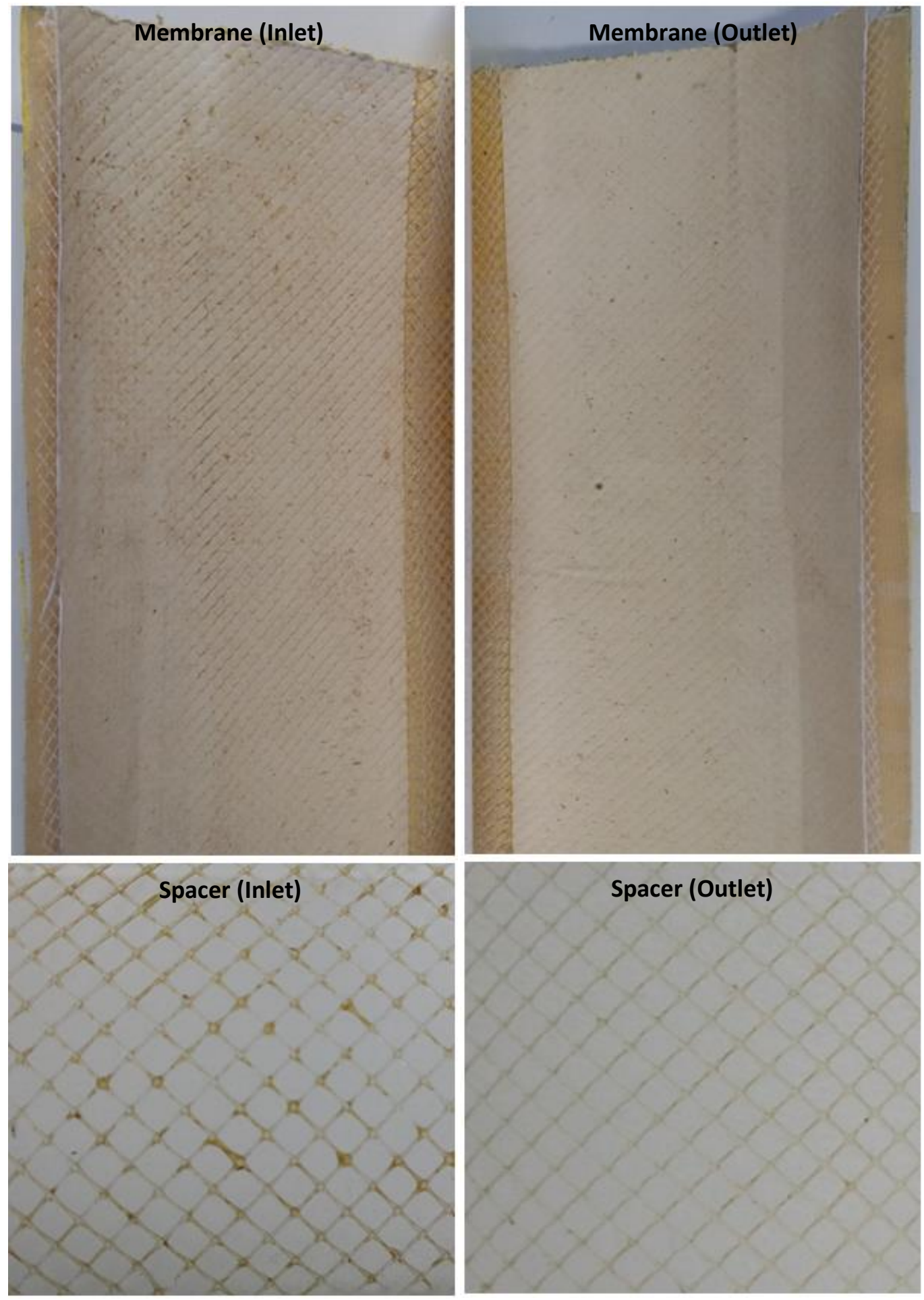


Figure 7

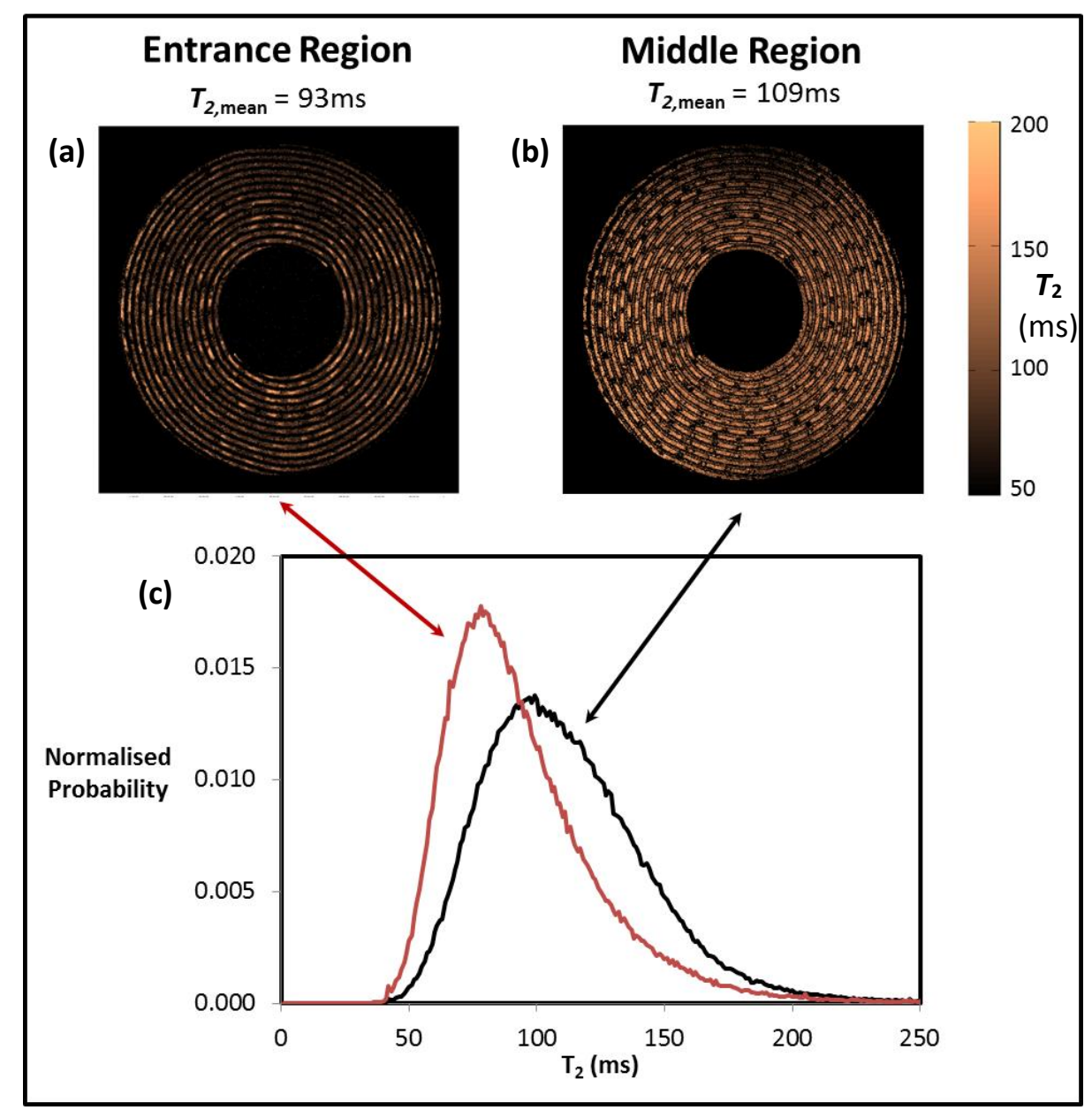


Figure 8
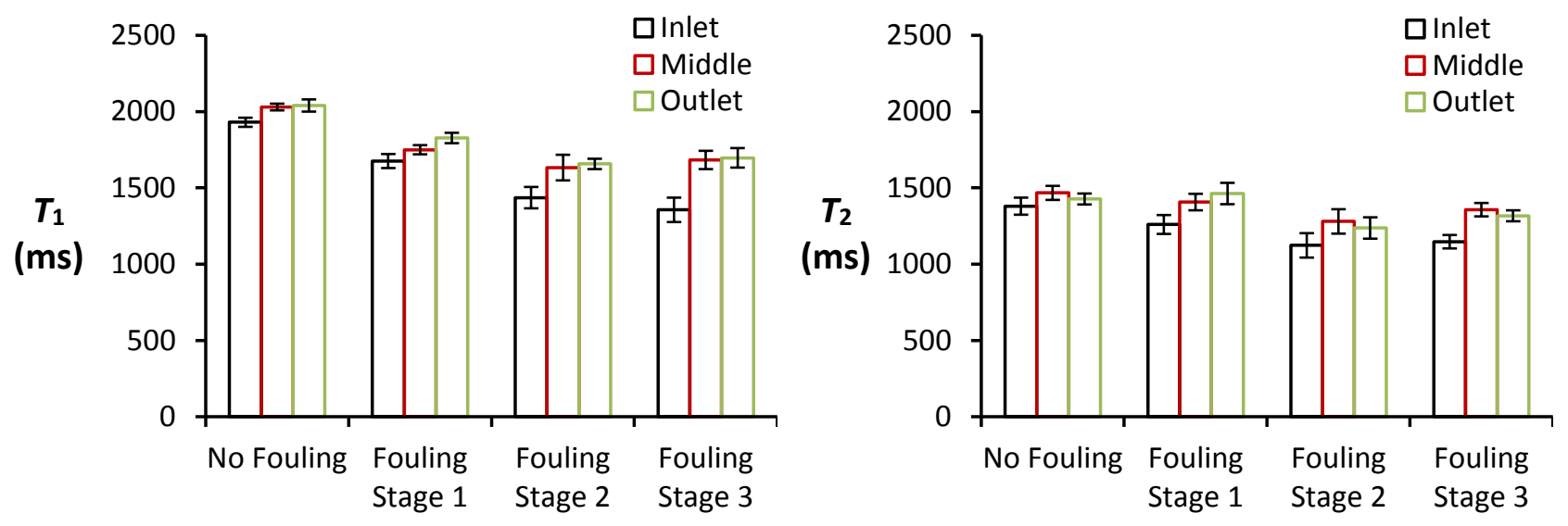
Figure 9
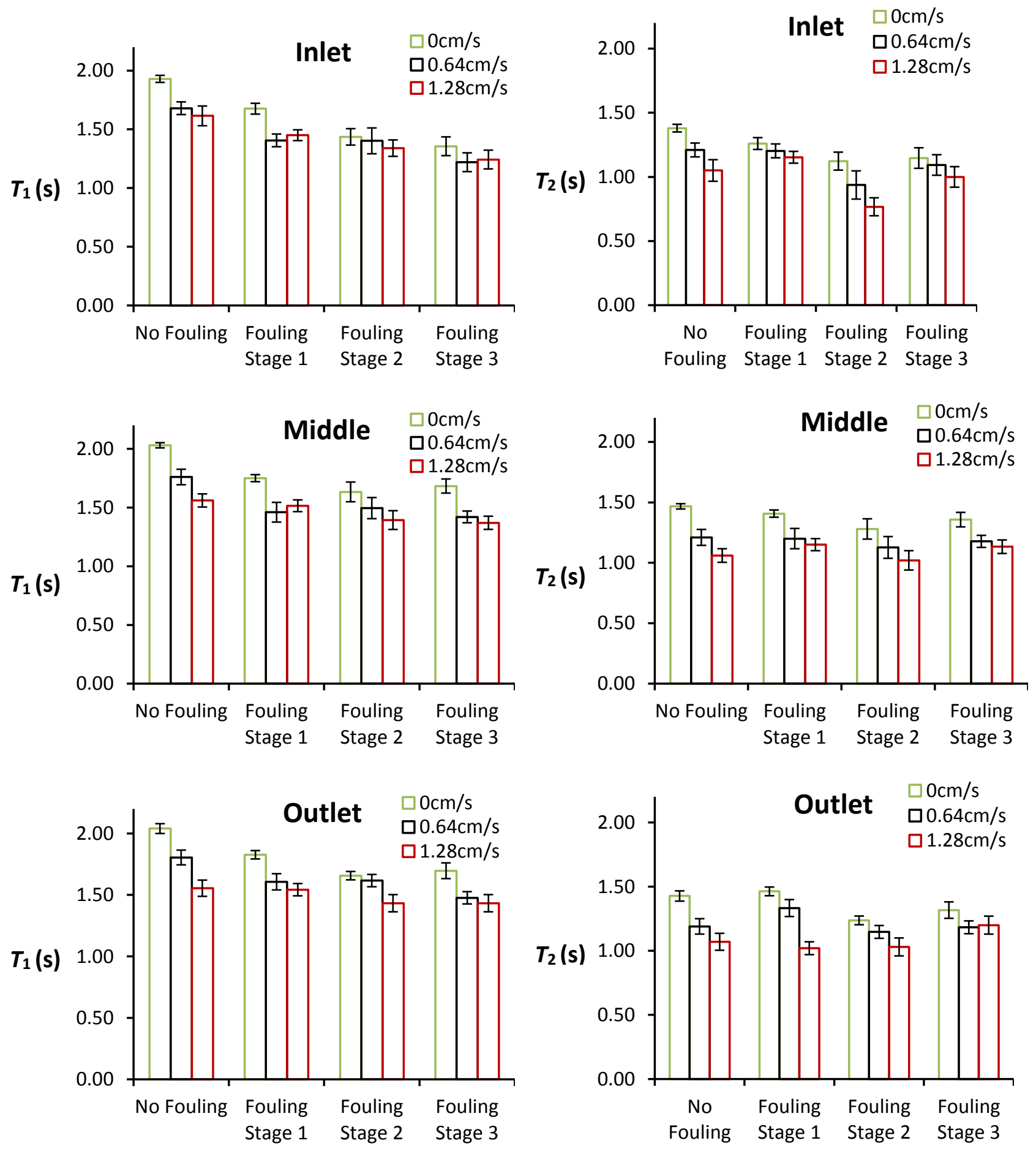
Figure 10
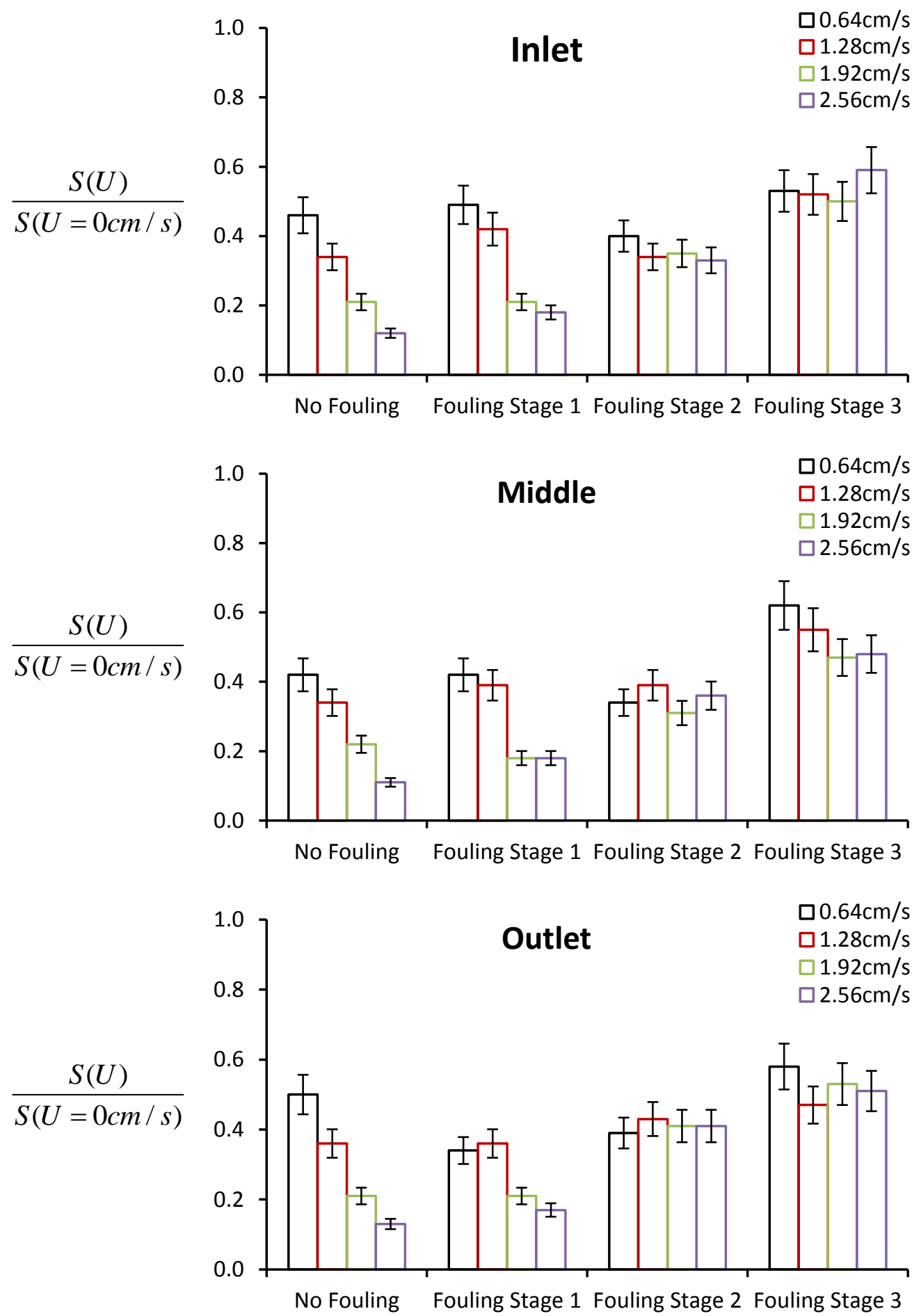